\title{
Process-based VOCs Source Profiles and Contributions to Ozone Formation in Typical Organic Solvent-used Industries in Hangzhou
}

\author{
Zhinian $\mathrm{Li}^{1,2}$, Wenjuan $\mathrm{Li}^{{ }^{*}}$, Rong $\mathrm{Zhou}^{1}$, Xiaoping Miao ${ }^{1}$, Jianhai Lu${ }^{1}$, \\ Zhongren Wang ${ }^{1}$, Zhongping Yang ${ }^{1}$, Jian $\mathbf{W u}^{{ }^{*}}$
}

${ }^{1}$ Institute of Air Pollution Prevention and Control, Eco-Environmental Science Research and Design Institute of Zhejiang Province, Hangzhou 310007, China

${ }^{2}$ United Chemical Reaction Engineering Institute, College of Chemical and Biological Engineering, Zhejiang University, Hangzhou 310007, China

\section{ABSTRACT}

The solvent-used industry plays an important role in volatile organic compounds (VOCs) emission, which has caused an increasing concern. Herein, VOCs samples collected before and after treatments from the painting industry, printing industry and printing \& dyeing industry in Hangzhou were measured. Then, the VOCs removal efficiencies of different treatments were detailedly investigated. Among them, high-temperature incineration technology achieved the highest VOCs removal efficiency, averaging 93.0\%. Process-based source profiles suggested that aromatics and alkanes accounted for more than $76.5 \%$ of VOCs, mainly including toluene, styrene, $\mathrm{n}$-decane, $\mathrm{n}$-undecane and $\mathrm{n}$-dodecane. Furthermore, the ozone formation potentials (OFPs) based on processes suggested that toluene, meta-xylene, n-butene, styrene and ortho-xylene should be preferentially controlled to reduce the OFPs in painting industry and printing \& dyeing industry. For printing industry, the contributions of top five species to the OFPs were relatively balanced, which indicated these species should all be given more attention. Finally, the low-temperature plasma technology and the combined technology of activated carbon adsorption with condensation were found to reduce the OFPs for their ability to preferably removing aromatics or olefins. The results were beneficial to develop effective VOCs abatement strategies and complemented the VOCs source profiles in solvent-used industries.

Received: January 11, 2021

Revised: May 30, 2021

Accepted: May 31, 2021

\section{${ }^{*}$ Corresponding Authors:}

Wenjuan Li

youyouyuehan@163.com

Jian Wu

wujian.ok@163.com

\section{Publisher:}

Taiwan Association for Aerosol Research

ISSN: $1680-8584$ print

ISSN: 2071-1409 online

(c) Copyright: The Author(s).

This is an open access article distributed under the terms of the Creative Commons Attribution License (CC BY 4.0), which permits unrestricted use, distribution, and reproduction in any medium, provided the original author and source are cited.

Keywords: Solvent-used industry, Volatile organic compounds, Source profile, Chemical reactivity, Ozone formation potentials

\section{INTRODUCTION}

Volatile organic compounds pose an enormous threat to human health because of their toxicity. Besides, they could also lead to a series of environmental problems, such as ground-level ozone and secondary organic aerosol formation (Thepanondh et al., 2011; Huang et al., 2014; Wu et al., 2017; Maji et al., 2019). Different kinds of VOCs have different chemical reactivity to the formation of ozone and secondary organic aerosol (SOA) (Ziemann and Atkinson, 2012; Xiong et al., 2020). Therefore, studying the emission characteristics and atmospheric chemical activity of anthropogenic VOCs emission source is an important basis for understanding the formation mechanism of air pollution and devising effective control policies (Li et al., 2020). In addition, source profiles, especially the localized, are important for source apportionment, which could provide data in support of air quality model simulation and air pollution control strategies (Song et al., 2008; Fu et al., 2020).

China is suffering from VOCs pollution. Industrial emissions such as the use of solvents and industrial combustions are the largest anthropogenic sources of VOCs (Wang et al., 2011; Huang et al., 2020). The organic solvent-used industry involved many categories of complex VOCs. As a 
result, most studies on the emissions and pollution characteristics of VOCs in solvent-used industry were sector-based and mainly focused on the researchers' convenient and interested regions (Zheng et al., 2013). Yuan et al. (2010) studied the VOCs source profiles of painting applications and printing processes in Beijing, China and found aromatics and heavier alkanes were the major species. Zhong et al. (2017) compiled VOCs source profiles from the surface painting industry in the Pearl River Delta region of China and found toluene and $\mathrm{m} / \mathrm{p}$-xylene were the major species in each of these six sectors. Recently, some researchers found emission profiles of some industries were process-oriented and established the process-based VOCs source profiles (Mo et al., 2015; Cheng et al., 2021). They pointed out the refined VOCs source profiles were more conducive to identifying emission characteristics and developing effective control strategies. For the solventused industry in Yangtze River Delta, reports on the compositions of VOCs and the potentials of ozone formation were still lacking, let alone refined VOCs source profiles. In addition, the measured efficiency of VOCs removal technologies in the solvent-used industry were also rarely reported.

The solvent-used industry occupied an important position in Yangtze River Delta, especially for Zhejiang Province. Some studies indicated VOCs emissions from solvent-used industry accounted for more than $50 \%$ of the total emissions in Zhejiang province (Fu et al., 2013; Wu et al., 2015). Hangzhou, the capital of Zhejiang province, will be the host city of the 2022 Asian Games. Studying the emission characteristics and the VOCs removal efficiency of mainstream technologies of typical processes in solvent-used industries in Hangzhou would contribute to the air quality assurance of the Asian Games.

In this study, VOCs samples before and after different treatments in the solvent-used processes were collected and analyzed. The VOCs removal efficiencies of different treatments were evaluated. Then, process-based VOCs emission factors and source profiles were built. Furthermore, the VOCs emission characteristics of different processes were analyzed, and their OFPs based on processes were calculated. Finally, the effects on source profile and OFPs of different treatments were discussed. This study mainly concentrated on process-based VOCs characteristics in typical solvent-used industries, which helped to precisely identify the emission characterization and effectively control the VOCs emission to relieve secondary pollution.

\section{MATERIALS AND METHODS}

\subsection{Identification of Sources of Solvent-used Industries}

From the results of emissions inventories, painting industry, printing industry and printing \& dyeing industry were considered to be the dominant sources of VOCs emission in solvent-used industries in Hangzhou (Lu et al., 2018). In this study, the typical companies were selected in corresponding industries. In addition, the main pollution-producing processes and the mainstream treatment measures of selected companies were comprehensively considered.

\subsection{Sampling Information and Methods}

Seven companies in Hangzhou were selected in this study, including 1 automobile spraying company and 2 metal product spraying companies representing painting industry, 2 printing companies representing printing industry and 2 printing \& dyeing companies representing printing \& dyeing industry. In order to study the efficiencies of VOCs treatment technologies and their influence on source profiles and OFPs, the VOCs samples before and after treatment facilities were collected in different processes strictly following the specification HJ/T 397-2007 (Technical specifications for emission monitoring of stationary source) and the standard HJ 7322014 (Emission from stationary sources-sampling of volatile organic compounds-bags methods). A total of 19 VOCs samples emitted from the 10 processes were chosen in this study. The basic information of companies, sampling sites and the amount of samples were shown in Table S1. The sampling site was located in the center of the stack without apparent turbulence; the sampling collection time for each sample was $8 \mathrm{~min}$. During the sampling process, flow-limiting valves were used to ensure that the samples were collected at a constant speed. The schematic diagram of VOCs sampling system was shown in Fig. 1. When the sampling volume reached about $80 \%$ of the maximum volume of the gas bag, the sampling ended, and then the vacuum pump was turned off. The sampling processes were done when factories were in good working conditions. 


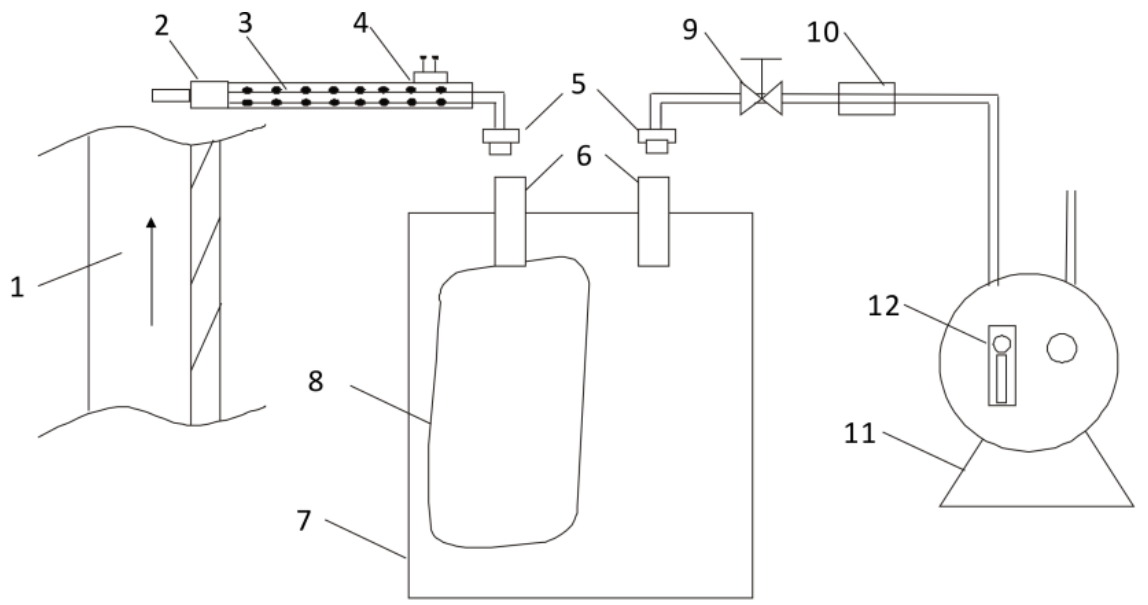

1: Stack; 2: Glass cotton filter; 3: Teflon connection tube; 4: Heating sampling tube

5: Anode of fast joint; 6: Cathode of fast joint; 7: Vacuum chamber; 8: Sampling bag;

9: Valve; 10: Activated carbon filter; 11: Vacuum pump; 12: Flowmeter

Fig. 1. Schematic diagram of VOCs sampling system.

Teflon bags (E-Switch, 1L, purchased from E-Switch official store in Shanghai) cleaned with high purity nitrogen (>99.999\%) at least three times and evacuated in the laboratory. Before sampling, the bags were rinsed thrice with the sample gases.

\subsection{VOCs Analysis}

VOCs samples were analyzed according to the EPA TO-15 (1999) method with gas chromatography-mass spectrometry (GC-MS; Agilent 7890A/5975C, USA) and the EPA/600-R98/161 method with gas chromatograph which had a flame ionization detector (FID). Briefly, $300 \mathrm{~mL}$ diluted sample was pumped into a preconcentrator with a three-stage trapping system (Model 7100, Entech Instruments, USA). Then the concentrated sample was injected into the gas chromatograph (GC). The $\mathrm{GC}$ oven temperature was set initially to $-10^{\circ} \mathrm{C}$, held for 5 mins, and then increased to $180^{\circ} \mathrm{C}$ at $5^{\circ} \mathrm{C} \mathrm{min}{ }^{-1}$ and to $200^{\circ} \mathrm{C}$ at $20^{\circ} \mathrm{C} \mathrm{min}{ }^{-1}$. An DB-624 capillary column $(60 \mathrm{~m} \times 0.25 \mathrm{~mm} \times 1.4 \mu \mathrm{m}$; Agilent Technologies, USA) and an HP-PLOT Q PT capillary column $(30 \mathrm{~m} \times 0.32 \mathrm{~mm} \times 20 \mu \mathrm{m}$; Agilent Technologies, USA) were used to separate the mixture. The mass spectrometer was operated in scan mode and scanned 35-300 amu after 12.0 mins. The ionization method was electron impacting and the source temperature was $230^{\circ} \mathrm{C}$. The Photochemical Assessment Monitoring Station (PAMS; 57 compounds) and Toxic Organic-15 (TO-15; 65 compounds) standard mixtures were used to calibrate the GC-MS/FID system that measured the C2-C12 VOCs. Calibration curves were made by the standard mixtures at five concentrations, ranging from 0.5 to $100 \mathrm{ppbv}$. The correlation coefficients of each curve were greater than 0.99 , and the method detection limit (MDL) of individual species ranged from 0.09 to $0.22 \mathrm{ppbv}$. In this study, a total of 109 VOCs substances were analyzed and the TVOCs (total VOCs concentrations) was the sum of the concentrations of individual VOCs. The weighted percentage of certain VOCs in the sample was its concentration to the total VOCs concentration. For high concentration samples, the pre-detections of the total VOCs concentration were firstly made to ensure the appropriate dilution ratio. Since the concentration of different VOCs in a sample sometimes differ greatly, there were different dilution ratio for quantifying different VOCs (Cheng et al., 2021).

Three VOCs with known concentrations, including bromochloromethane, 1,4-difurobenzene and 1-bromo-3-fluorobenzene, were used as internal standards for each sample to calibrate the system. The precision of each species was within $10 \%$. A standard gas ( $5 \mathrm{ppb}$ ) was measured each day to check the stability of the system. For quality assurance and quality control, new vacuum sampling bags were used to collect the samples. If sampling bags had to be repeatedly used, they were required to undergo a blank experiment prior to the sampling process. And no target compound (Lower than the detection limits) was detected in laboratory and transportation blank 
samples during the analysis. One parallel sample was analyzed for every ten samples, and the relative deviations of the target compounds in the parallel sample were less than $30 \%$.

\subsection{Evaluation of Removal Efficiency}

The measured removal efficiency of one VOCs treatment technology was calculated according to Eq. (1):

$\eta=\frac{C_{\text {in }}-C_{\text {out }}}{C_{\text {in }}}$

where $\eta$ was the removal efficiency, \%; $C_{\text {in }}$ and $C_{\text {out }}$ respectively referred to the TVOCs of inlet and outlet of one VOCs control device, $\mathrm{mg} \mathrm{m}^{-3}$.

\subsection{Calculation of Emission Factor}

VOCs emissions of typical solvent-used industry were mainly from the use of paint, paint thinners, hardeners, adhesives and detergents etc. Based on the total annual consumption of VOCs-containing raw and auxiliary material, its percentage of VOCs, collective efficiencies and measured removal efficiencies of VOCs treatment technologies in certain process, the mass balance approach was used to estimate VOCs emission (Cheng et al., 2018). The related data were presented in SI Table S2. Accordingly, the process-based VOC emission factors could be established according to Eq. (2).

$$
E F=\frac{\sum_{i=1}^{n} M_{i} \times C_{i}}{\sum_{i=1}^{n} M_{i}}(1-\omega \eta)
$$

where EF was the VOCs emission factor per unit of VOCs-containing raw and auxiliary material, $\mathrm{kg} \mathrm{kg}^{-1} ; \mathrm{Mi}_{\mathrm{i}}$ was the amount of raw or auxiliary material $\mathrm{i}$ used, $\mathrm{kg} ; \mathrm{C}_{\mathrm{i}}$ was the VOCs content of raw or auxiliary material $i, \% ; \omega$ was the collective efficiencies; $\eta$ was the removal efficiencies of VOCs treatment technologies.

\subsection{Estimation of the Photochemical Reactivity (PR)}

The methodologies of measuring the photochemical reactions mainly include $\mathrm{OH}$ radical reaction rate method, equivalent-propylene concentration method and maximum incremental reaction activity method (MIR), etc. (Atkinson, 1990; Chameides et al., 1992; Derwent et al., 1996; Carter, 2010). In this study, MIR was used to calculate the OFPs of VOCs emitted from the solvent-used industries in Hangzhou (Martien et al., 2003; Liu et al., 2016). The calculation can be expressed by Eq. (3):

$$
O F P_{j}=\sum_{j=1}^{n} X_{i j} \times M I R_{i}
$$

where OFP $\mathrm{P}_{\mathrm{j}}$ referred to the ozone formation potentials of the jth process, $\mathrm{g} \mathrm{O}_{3}(\mathrm{~g} \mathrm{VOCs})^{-1} \cdot \mathrm{X}_{\mathrm{ij}}$ referred to the weighted percentage of ith VOCs in the jth process. MIRi referred to the MIR value of the ith VOC species, $\mathrm{g} \mathrm{O}_{3}\left(\mathrm{~g} \mathrm{VOCs}^{-1}\right.$, and these values from (Carter, 2010) were presented in Table $\mathrm{S} 6$ of the supplementary materials.

\section{RESULTS AND DISCUSSION}

\subsection{The VOCs Removal Efficiencies of Treatment Technologies and Process- based VOC Emission Factors}

The removal efficiencies of VOCs treatment technologies were shown in Table 1. Among them, 
Table 1. The process-based VOC emission factors and the removal efficiencies of VOCs treatment technologies.

\begin{tabular}{|c|c|c|c|c|c|}
\hline $\begin{array}{l}\text { Company } \\
\text { code }\end{array}$ & Source & VOCs treatment technology & Process & $\begin{array}{l}\text { Removal } \\
\text { efficiency (\%) }\end{array}$ & $\begin{array}{l}\text { Emission factor } \\
\left(\mathrm{kg} \mathrm{kg}^{-1}\right)\end{array}$ \\
\hline \multirow[t]{2}{*}{ A } & Color steel spraying & Low-temperature plasma & Paint spraying & 5.8 & 0.34 \\
\hline & & & Drying & 11.9 & 0.34 \\
\hline \multirow[t]{2}{*}{ B } & Car spraying & High-temperature incineration & Electrophoresis drying & 90.2 & 0.06 \\
\hline & & & Spray drying & 95.9 & 0.11 \\
\hline C & $\begin{array}{l}\text { Metal material } \\
\text { spraying }\end{array}$ & $\begin{array}{l}\text { Adsorption-desorption combined } \\
\text { with catalytic combustion }\end{array}$ & $\begin{array}{l}\text { Paint spraying and } \\
\text { drying }\end{array}$ & 36.8 & 0.18 \\
\hline D & Printing & High-temperature incineration & Coating & 93.0 & 0.20 \\
\hline$E$ & Printing & Activated carbon adsorption & Printing & -43.5 & 0.79 \\
\hline $\mathrm{F}$ & Post-printing coating & $\begin{array}{l}\text { Activated carbon adsorption } \\
\text { combined with condensation }\end{array}$ & Coating & 41.3 & 0.38 \\
\hline G & $\begin{array}{l}\text { Stereotype of } \\
\text { synthetic fiber }\end{array}$ & Water spray combined with static & Stereotype & 24.1 & 0.46 \\
\hline
\end{tabular}

the removal efficiency of high-temperature incineration was the highest. The VOCs removal efficiency of high-temperature incineration was mainly influenced by temperature, gas flow, and VOCs concentration etc. (Shao, 2019). In the three applications, the VOCs removal efficiencies of high-temperature incineration were greater than $90.0 \%$ since the furnace temperatures and VOCs concentrations were relatively high and the flow rates were only $5000 \mathrm{~m}^{3} \mathrm{~h}^{-1}$. The removal efficiencies of activated carbon adsorption combined with condensation technology and adsorption-desorption combined with catalytic combustion technology were medium, $41.3 \%$ and $36.8 \%$, respectively. In addition, the water spray combined with electrostatic technology and low-temperature plasma technology had low removal efficiencies. Removal efficiency of activated carbon adsorption technology was $-43.5 \%$. The adsorption of activated carbon was a phase equilibrium process of adsorption and dissociation. When the adsorption was saturated without timely replacement or desorption regeneration, the desorption surpassed the adsorption, then the removal efficiency was negative (Khan and Kr. Ghoshal, 2000). Therefore, the enhanced supervision and maintenance for applying activated carbon adsorption technology were urgently needed in Hangzhou.

The measured emission factors of different processes in solvent-used industry varied greatly. As shown in Table 1, printing process had the highest emission factor of $0.79 \mathrm{~kg} \mathrm{~kg}^{-1}$, which was much higher than the average of printing industry in Zhejiang province $\left(0.48 \mathrm{~kg} \mathrm{~kg}^{-1}\right.$, calculated by mass balance approach) (Wang et al., 2018). This may be related to the extensive use of solvent-based raw and auxiliary materials and the low removal efficiency of activated carbon adsorption. The emission factors of post-printing coating, stereotype of synthetic fiber, paint spraying and drying had relatively high emission factors, with a range of 0.34 to $0.49 \mathrm{~kg} \mathrm{~kg}^{-1}$. And the emission factor of electrophoresis drying was the lowest $\left(0.06 \mathrm{~kg} \mathrm{~kg}^{-1}\right)$, far below the average level of metal painting industry in Zhejiang province (Wang et al., 2020). This may be related to low VOCs content of electrophoretic paint and high removal efficiency of high-temperature incineration. The emission factors differed by dozens of times in different processes, which also indicated the study of process-based emission characteristics was necessary.

\subsection{Mass Concentration Ratio of VOCs}

In this study, total 109 VOCs substances were detected, and 89 VOCs (>99\%) from collected samples were normalized by weight, including alkanes, alkenes, aromatics, chlorinated hydrocarbon, alcohols, aldehydes, ketones, etc. The top 20 VOCs (>90\%) were selected for detail analysis, which were shown in Tables S3, S4 and S5. The 20 VOCs were divided into four categories: alkanes, alkenes, aromatics and others.

As shown in Fig. 2, aromatics and alkanes accounted for more than $76.5 \%$ in all samples. In paint spraying and drying process of Company A, aromatics were the dominant VOCs, with contributions of $83.4 \%$ and $84.3 \%$, respectively. The alkanes followed, accounting for $11.8 \%$ and $12.6 \%$, respectively. In electrophoresis drying and spray drying process of Company $\mathrm{B}$, the measured VOCs showed some difference. In electrophoresis drying process, aromatics were dominant (61.6\%) and 


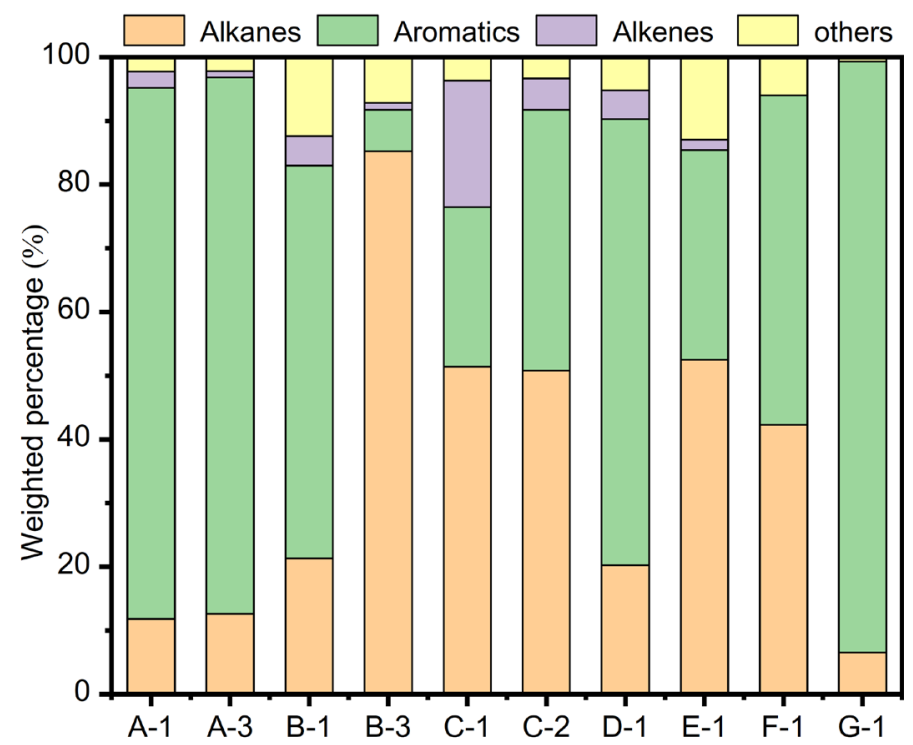

Fig. 2. The mass concentration ratios of inlet VOCs treatment facilities of different processes.

alkanes accounted for $21.3 \%$. In spray drying process, alkanes dominated, accounting for $85.2 \%$, and aromatics only accounted for $6.5 \%$. In paint spraying and drying process of Company $\mathrm{C}$, the contributions of alkanes were very similar, about $50 \%$. But the contribution of aromatics in paint spraying process was $16.0 \%$, higher than that in drying process. Yuan et al. (2010) and Tian et al. (2017) found the VOCs emitted from the paint spraying process were mainly aromatics and alkanes, which were similar to the results in this study.

In coating process of Company D, aromatics accounted for $69.9 \%$, and alkanes accounted for $20.2 \%$. In printing process of Company E, alkanes (52.5\%) contributed more than aromatics (33.0\%). There were some differences compared with other studies. The VOCs emitted from the printing industry in Beijing were mainly alkanes and aromatics, accounted for $66.7 \%$ and $31.6 \%$, respectively (Yuan et al., 2010). But VOCs emitted by the printing industry in Nanjing were mainly alcohols and alkanes (Xie et al., 2018). These differences may be caused by the different paint used and local standard or polies implemented in printing industry.

In printing \& dyeing industry, aromatics and alkanes accounted for more than $95.4 \%$. In the post-printing coating process of Company $F$, aromatics and alkanes respectively accounted for $52.5 \%$ and $42.9 \%$. As for the fiber stereotype process of Company $\mathrm{G}$, there were basically all aromatics (up to 92.1\%). In Han's research, alkanes, alcohols and benzene were the main VOCs in the exhaust gas from the setting machine (Han, 2017). Zhang et al. (2020) stated that the main components of textile printing \& dyeing were alkanes (34\%), OVOCs (25\%) and aromatic hydrocarbons (23\%) in Zhengzhou. These were quite different from our research. Nevertheless, the exhaust gas was collected from the heat setting stage of cotton in Han's (2017) research and the exhaust gas was from the fugitive emission in Zhang et al.'s (2020) research. These differences in processed materials and sampling methods etc. made direct comparisons difficult.

\subsection{Process-based VOCs Source Profiles}

As a variety of VOCs were detected and the top 10 species contributed more than $90 \%$ or even $95 \%$ of the total VOCs concentration, so simplified process-based VOCs source profiles were formed to highlight the necessary pollution characteristics.

\subsubsection{Painting industry}

Fig. 3 showed the main VOCs compositions in different processes of painting industry, mainly including toluene, $\mathrm{m}$-xylene, $\mathrm{n}$-undecane, $\mathrm{n}$-decane, $\mathrm{n}$-butene and styrene. The details were shown in Table S3. As can be seen, the paint spraying process of Company A mainly produced toluene, accounting for $70.9 \%$. And the TEX species (toluene, ethylbenzene and $\mathrm{m}$-xylene) were the main species produced in drying process, with toluene accounting for the largest percentage (40.2\%), 


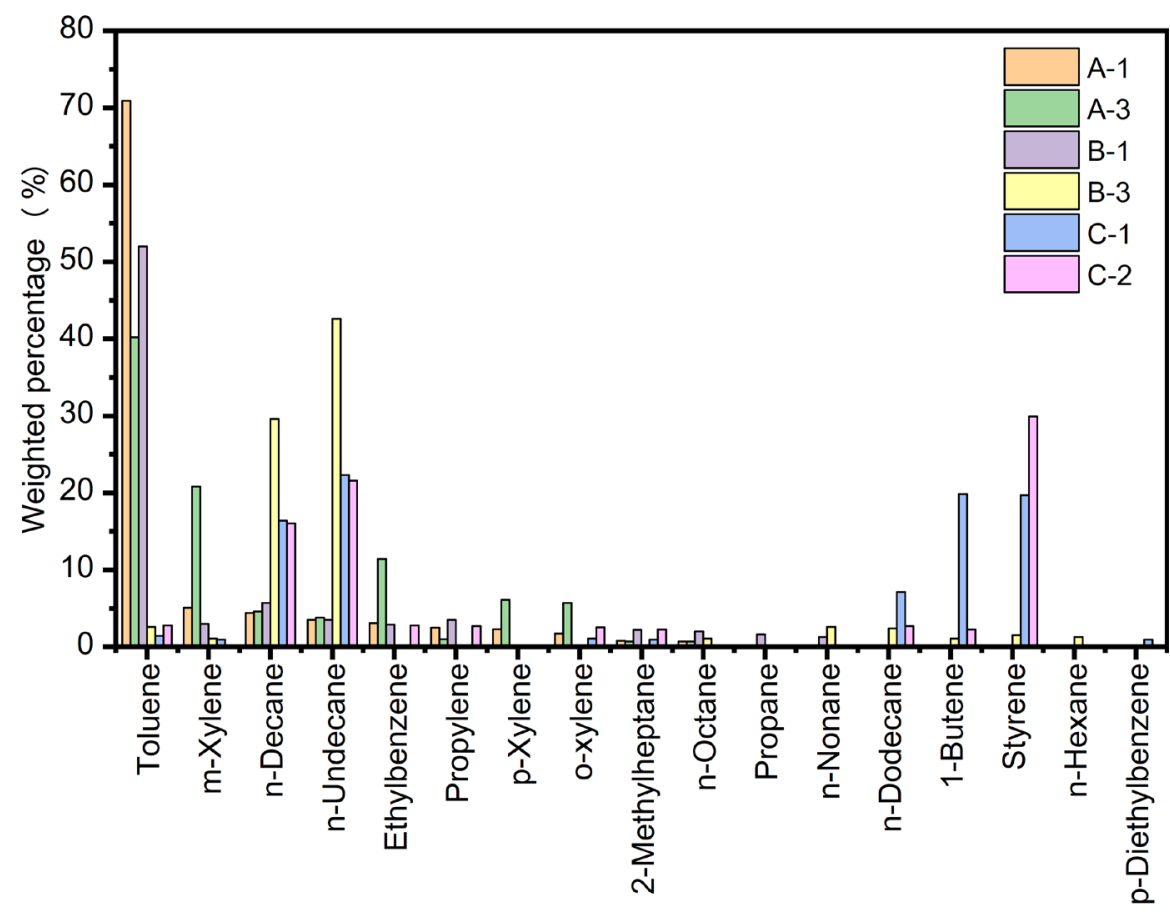

Fig. 3. Top 10 VOCs from different processes of painting industry.

followed by m-xylene (20.8\%) and ethylbenzene (11.4\%). As for Company B, the process of electrophoresis drying mainly produced toluene, accounting for $52.0 \%$, while the spray drying process mainly produced n-undecane and n-decane, accounting for $42.6 \%$ and $29.6 \%$, respectively. The major species from drying process of Company $\mathrm{C}$ were $\mathrm{n}$-undecane, styrene, butene and n-decane, accounting for $22.3 \%, 19.8 \%, 19.7 \%$ and $16.4 \%$, respectively; and the painting process mainly produced styrene, $n$-undecane and $n$-decane, accounting for $29.9 \%, 21.6 \%$ and $16.0 \%$, respectively. In total, the aromatics and the heavy hydrocarbons were the dominant VOCs produced in painting industry, which demonstrated that the solvent-based products still played an important role in the painting industry in Hangzhou (Li et al., 2018; Wu et al., 2020).

\subsubsection{Printing industry}

The major VOCs compositions in coating and printing process of printing industry were illustrated in Fig. 4. In coating workshop of Company D, propylbenzene and n-undecane accounted for $24.5 \%$ and $11.8 \%$, respectively. The other VOCs contributing over $5 \%$ were m-ethyltoluene (9.4\%), 1,2,4-trimethylbenzene (7.0\%), and 1,2,3-trimethylbenzene (6.3\%). The exhaust gas from printing workshop of Company $\mathrm{E}$ were mainly n-undecane, $\mathrm{n}$-dodecane, styrene and $\mathrm{n}$-decane, accounting for $27.7 \%, 16.2 \%, 8.9 \%$ and $8.6 \%$, respectively. Compared with other studies, the compositions of VOCs in Hangzhou from printing industry were quite different. Isopropanol, ethanol and 1-hexene were the main VOCs emitted by the gravure process in Nanjing (Xie et al., 2018). The printing industry in the Pearl River Delta mainly emitted ethyl acetate, isopropanol, 2-butanone and toluene (Yang et al., 2013). The source profile was not only closely related to raw materials and products but also inseparable from the process technology. Thus, developing the localized process-based source profiles was imperative, which could help us identify emission characteristics and formulate better control strategies.

\subsubsection{Printing \& dyeing industry}

As shown in Fig. 5, toluene was the most abundant species in both post-printing coating process and stereotype of synthetic fiber, accounting for $46.1 \%$ and $91.7 \%$, respectively. In post-printing coating process of Company $\mathrm{F}$, the other major VOCs were $n$-undecane and n-decane, accounting for $17.8 \%$ and $11.7 \%$, respectively. Compared with the components emitted from painting industry and printing industry, the VOCs from the printing \& dyeing industry were less diverse. 


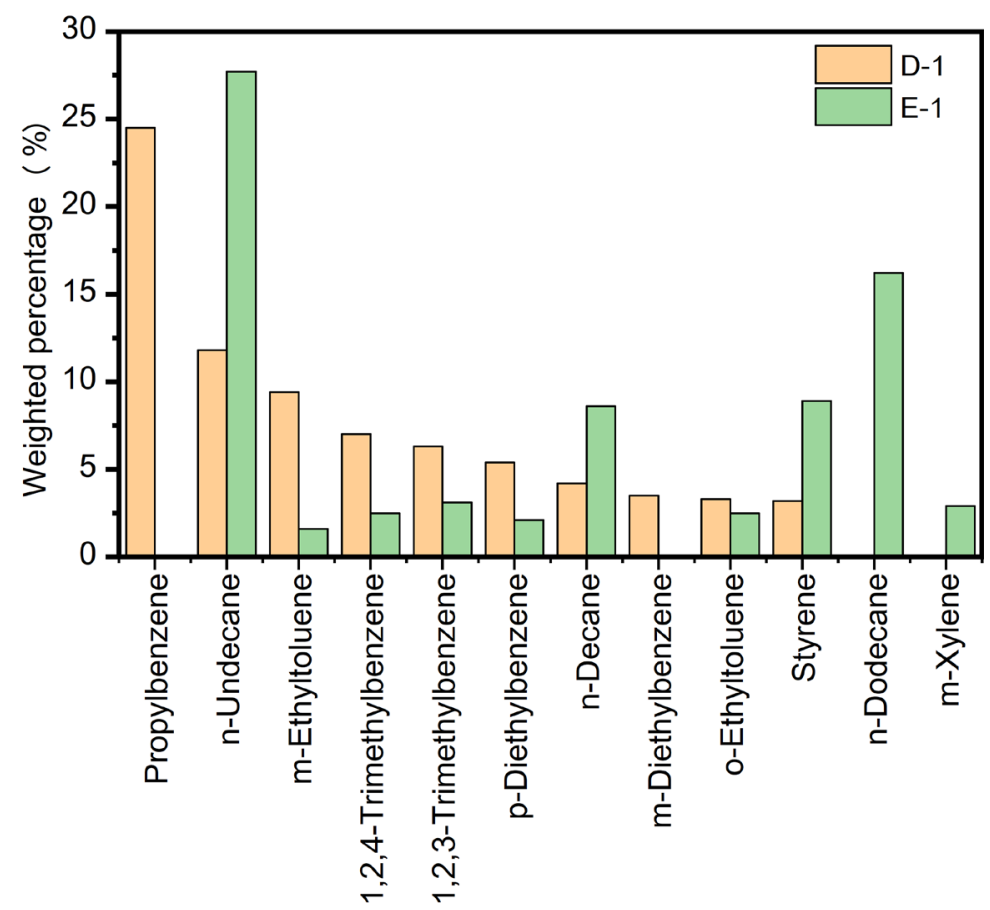

Fig. 4. Top 10 VOCs from different process of printing industry.

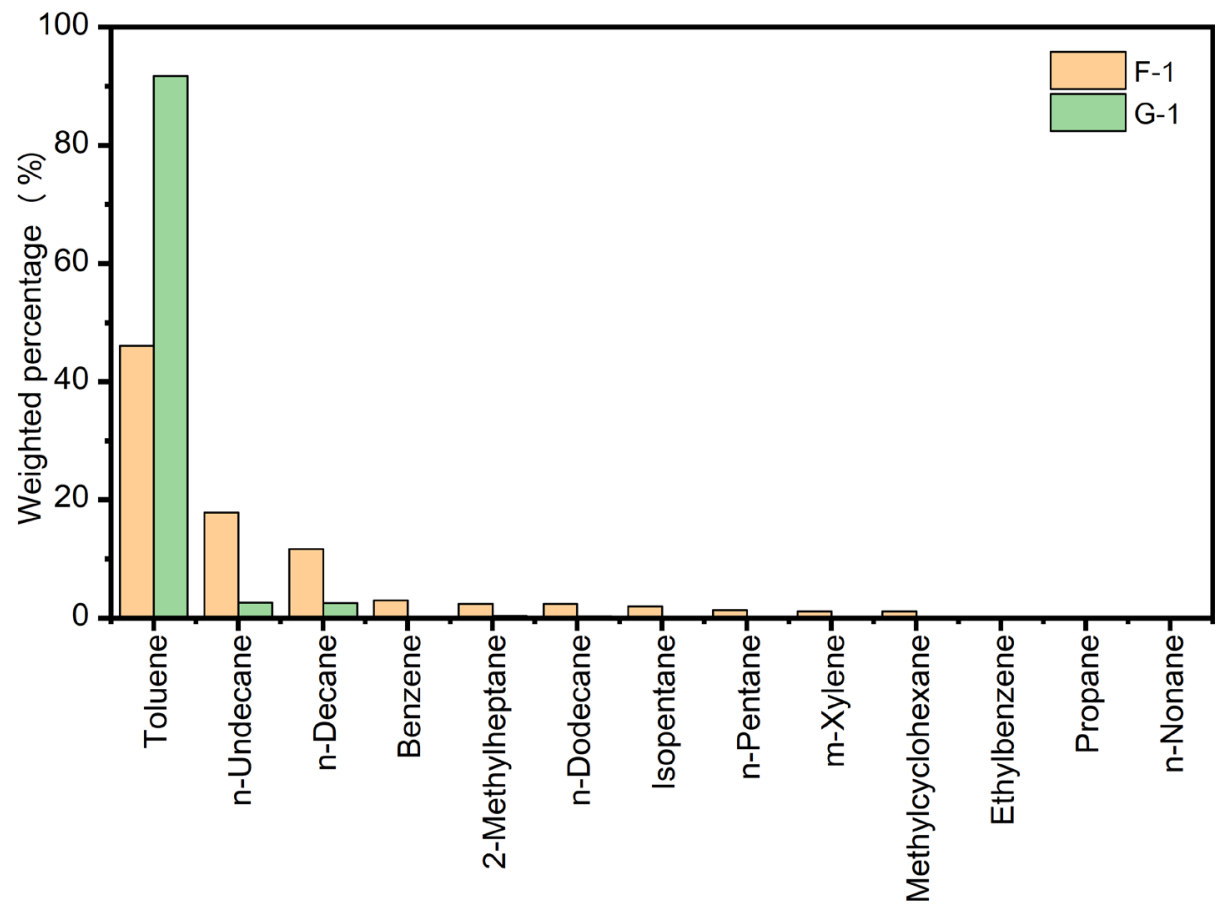

Fig. 5. Top 10 VOCs from different processes of printing \& dyeing industry.

This was mainly related to the relatively simple types of solvent used in printing \& dyeing industry.

\subsection{Process-based Ozone Formation Potentials}

As can be seen from the Fig. 6, the OFPs of VOCs emitted from different processes in different industries varied greatly. The OFPs of VOCs in drying process of coating Company A was the highest, $5.0 \mathrm{~g} \mathrm{~g}^{-1}$, followed by that in coating workshop of Company $\mathrm{D}$ and paint spraying process 


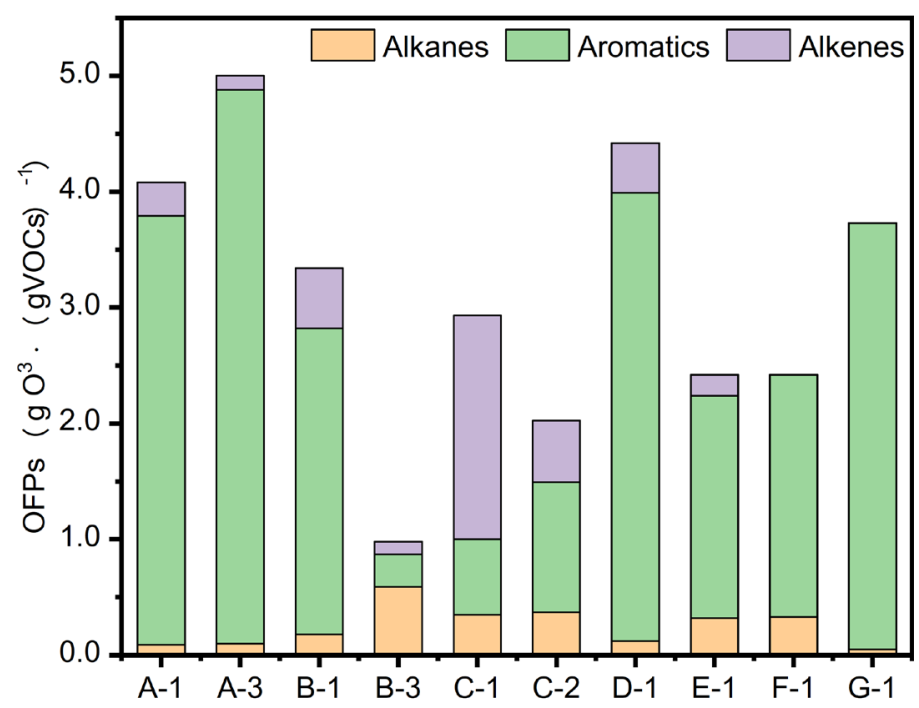

Fig. 6. The distribution of VOCs chemical groups to the total OFPs in different processes.

of Company A, and their OFPs were $4.4 \mathrm{~g} \mathrm{~g}^{-1}$ and $4.1 \mathrm{~g} \mathrm{~g}^{-1}$, respectively. The VOCs emitted by spray drying process of company $B$ had the lowest OFPs, which was $1.0 \mathrm{~g} \mathrm{~g}^{-1}$. The OFPs of VOCs emitted by solvent-used industries in Hangzhou almost derived from aromatics, olefins and alkanes. Specifically, the contribution of aromatics to the OFPs was the highest except the spray drying process of Company B and drying process of Company C. Therefore, priority control should be given to the aromatics in solvent-used industries.

The total percentages of top 5 species based on OFPs accounted for $50.6 \%-99.6 \%$ in all tested samples, as shown in Fig. 7. For specific components, toluene made a great contribution to both OFPs and emissions in paint spraying process of company $A$, electrophoretic drying process of Company $B$, post-printing coating of Company $F$ and stereotype process of Company $G$. In particular, the contribution of toluene to OFPs in post-print coating of Company $\mathrm{F}$ and stereotype of Company $\mathrm{G}$ even reached $75.8 \%$ and $98.3 \%$, respectively. Thus, toluene should be controlled first in these processes. The meta-xylene and toluene in drying process of Company A and styrene in paint spraying process of Company $C$ had higher contributions to OFPs and emission, which should be given priority to be controlled. As for the drying process of Company $\mathrm{C}$, n-butene contributed $65.8 \%$ to the OFPs with only $19.8 \%$ emission, which was the key component of control. However, the n-undecane and $n$-decane in spray drying process of Company $B$ had a great contribution to the OFPs, approching 46.7\%, which was quite different from its emissions (72.2\%). This was mainly due to the low reactivity of alkanes. For printing industry, 1,2,3-trimethylbenzene, m-ethyltoluene, 1,2,4-trimethylbenzene, propylbenzene and 1,3,5-trimethylbenzene were the major species contributing to OFPs in coating workshop of Company D. And 1,2,3-trimethylbenzene, $\mathrm{m}$ xylene, 1,2,4-trimethylbenzene, propylene and n-undecane were the top five species in printing workshop of Company E. The top five species contributing to the OFPs in these two processes were relatively low, only about $50 \%$, and the contributions of each species had little difference, which indicated that these species should all be given more attention without priority. Preferential species to control changed with different processes, which also demonstrated the necessity of process-based VOCs source profiles.

\subsection{The Effects of VOCs Treatments on VOCs Source Profiles and Ozone Formation Potentials}

The ozone formation potentials would be affected by VOCs treatment technologies through changing the VOCs source profiles. As can be seen in Table S3, the mass concentration ratios of toluene and propylene in the process of color steel spraying reduced greatly after low-temperature plasma treatment. Due to the lower ionization energy, aromatic hydrocarbons and olefins with higher MIR value were more likely to be ionized and degraded by low-temperature plasma technology compared with alkanes. From Table S5, the mass concentration ratios of most aromatics 


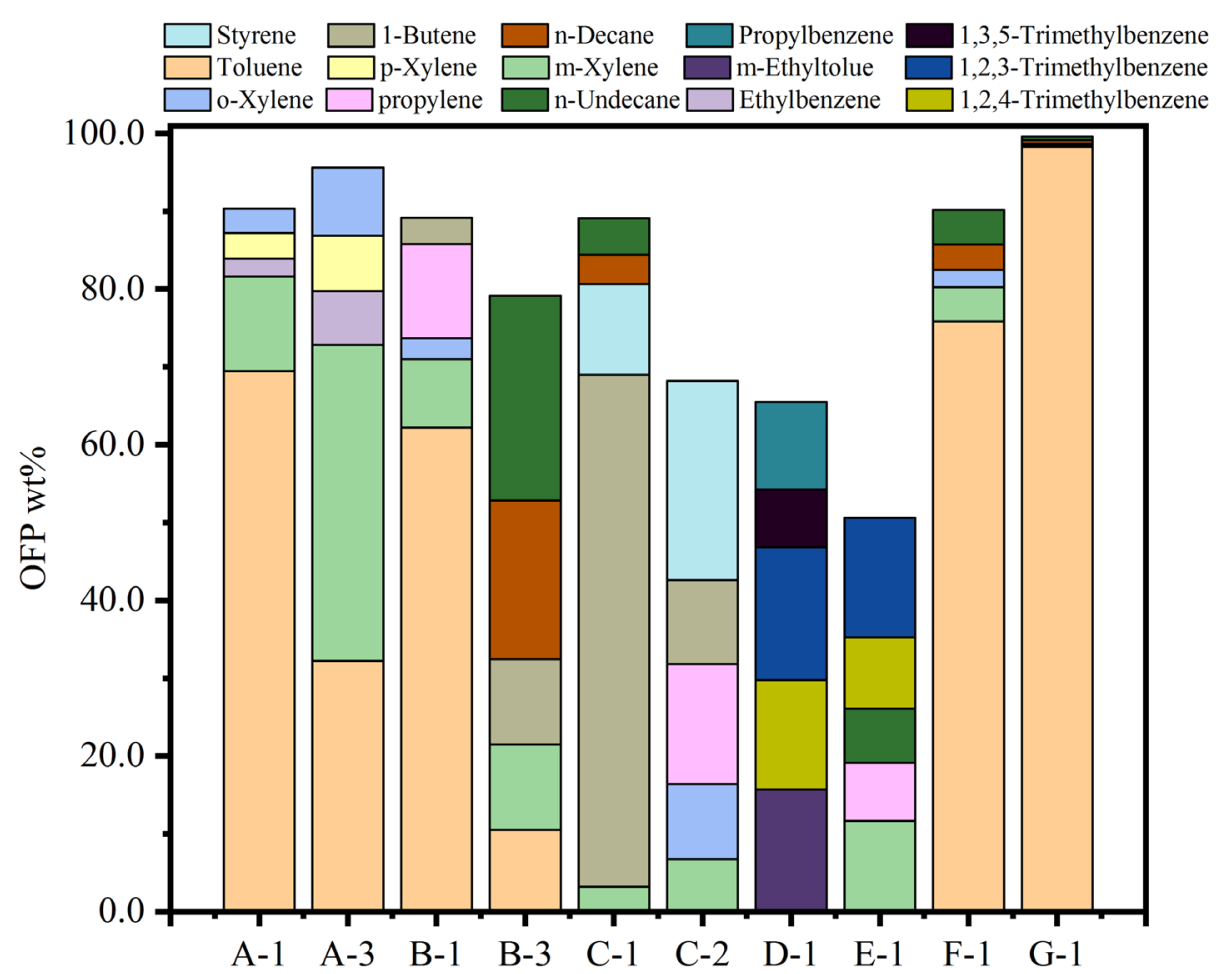

Fig. 7. The OFPs-based percentages on top 5 individual species in different processes of solventused industries.

and alkanes with higher boiling points except $n$-undecane in the process of post-printing coating decreased by the combined technology of activated carbon adsorption and condensation. This may be related to the better ability of the activated carbon adsorption combined with condensation technology to remove VOCs with higher boiling points. Therefore, the adoption of low-temperature plasma technology and the combined technology of activated carbon adsorption and condensation was beneficial to reduce the OFPs as shown in Fig. 8.

However, for the process of Company C, E and G (shown in Tables S3, S4 and S5), the VOCs source profiles changed little after the treatment of adsorption-desorption combined with catalytic combustion, activated carbon adsorption and water spray combined with electrostatic. These technologies had no selectivity to remove certain types of VOCs, especially highly reactive VOCs, thus had no ability to significantly reduce the OFPs for unit mass.

In addition, the pyrolysis and chemical reaction would be easy to occur at high temperature. So great differences existed in the VOCs source profiles after high-temperature incineration treatment in the process of company B and D, as shown in Tables S3 and S4. In the process of electrophoresis drying and spray drying of Company $B$, due to the pyrolysis of toluene, $n$-decane and $n$-undecane and subsequent recombination, the mass concentration ratios of $m$-xylene, styrene and 1-butene significantly increased. And in the coating process of Company D, the mass concentration ratios of m-ethyltoluene, $\mathrm{p}$-diethylbenzene and n-decane etc. in VOCs source profiles improved with the propylbenzene and $n$-undecane degrading. The mass concentration ratios of aromatics and olefins with high MIR went up after applying high-temperature incineration technology, so the OFPs increased, as shown in Fig. 8.

\section{CONCLUSIONS}

The VOCs removal efficiencies of different treatments and process-based VOCs emission factors were evaluated. Then, the local process-based VOCs source profiles were built and corresponding OFPs were calculated to screen out priority control species of VOCs. In addition, the effects of VOCs removal technologies on VOCs source profiles and OFPs were discussed. 


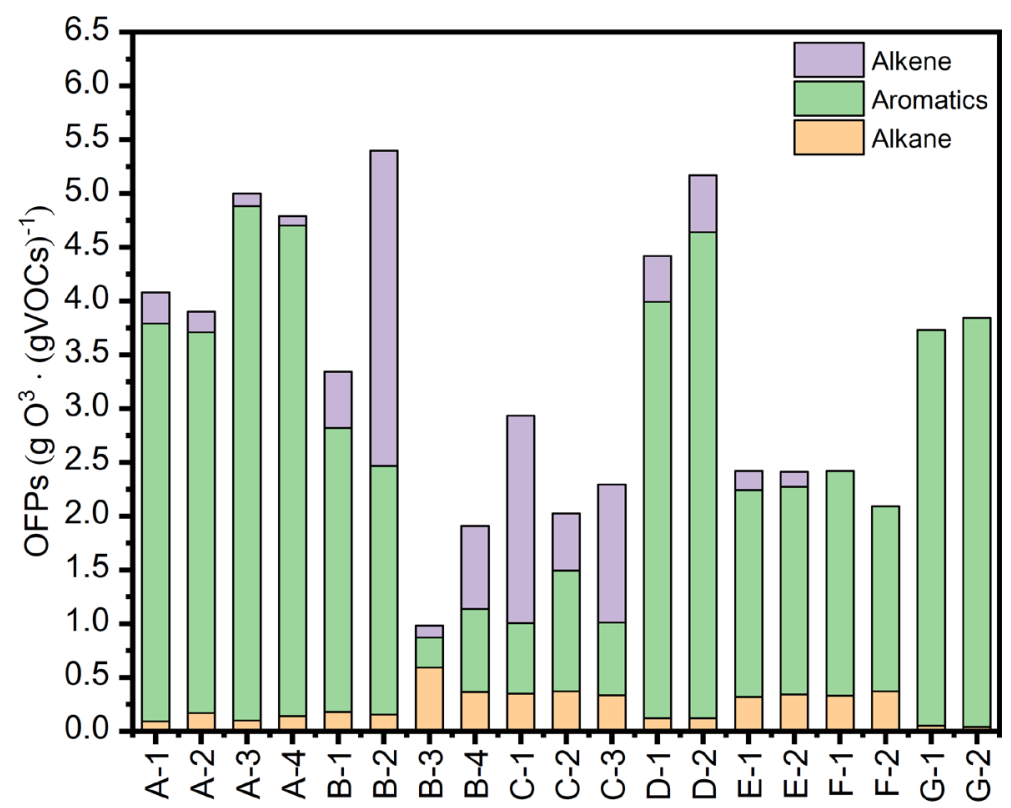

Fig. 8. Process-based OFPs profiles for unit mass before and after different treatments. (A: lowtemperature plasma; $\mathrm{B}$ : high-temperature incineration; $\mathrm{C}$ : adsorption-desorption with catalytic combustion; D: high-temperature incineration; E: activated carbon adsorption; F: activated carbon adsorption with condensation; G: water spraying with static electricity treatment.)

The removal efficiency of high-temperature incineration was highest, averagely $93.0 \%$. The emission factors of different processes varied greatly, ranging from 0.06 to $0.79 \mathrm{~kg} \mathrm{~kg}^{-1}$. The process-based VOCs source profiles showed aromatics and alkanes were the main VOCs in typical solvent-used industry in Hangzhou. And the aromatics was the largest contributor to OFPs for most processes, which indicated the priority should be given to controlling the aromatics to reduce OFPs.

More specifically, toluene, meta-xylene, n-butene, styrene and ortho-xylene should be preferentially controlled in painting industry and printing \& dyeing industry. For printing industry, the proportions of top five species in each process contributing to the OFPs were relatively low and balanced, which indicated that these species should be given more attention without priority.

Most technologies had no selectivity to remove certain types of VOCs. Nonetheless, the adoption of low-temperature plasma technology and activated carbon adsorption combined with condensation technology would be beneficial to remove aromatics and olefins with higher MIR, thus decreased OFPs. And the OFPs may increase due to the pyrolysis and chemical reaction after high-temperature incineration treatment.

The emission characteristics of VOCs proved the local process-based source profiles were significant and imperative. What's more, the process-based source profiles provided evidences for the precise control of VOCs pollution, which could also serve as an important supplement to the rough source profiles of solvent-used industries in Yangtze River Delta.

\section{ACKNOWLEDGMENTS}

This work was supported by the Financial Grant from the China Postdoctoral Science Foundation (No. 2020M671797) and National Key Research and Development Project (2018YFC0213806).

\section{SUPPLEMENTARY MATERIAL}

Supplementary material for this article can be found in the online version at https://doi. org/10.4209/aaqr.210008 


\section{REFERENCES}

Atkinson, R. (1990). Gas-phase tropospheric chemistry of organic compounds: A review. Atmos. Environ. 24, 1-41. https://doi.org/10.1016/0960-1686(90)90438-S

Babar, Z.B., Shareefdeen, Z. (2014). Management and control of air emissions from electronic industries. Clean Techno. Environ. Policy 16, 69-77. https://doi.org/10.1007/s10098-0130594-6

Carter, W.P.L. (2010). Development of the SAPRC-07 chemical mechanism. Atmos. Environ. 44, 5324-5335. https://doi.org/10.1016/j.atmosenv.2010.01.026

Chameides, W.L., Fehsenfeld, F., Rodgers, M.O., Cardelino, C., Martinez, J., Parrish, D., Lonneman, W., Lawson, D.R., Rasmussen, R.A., Zimmerman, P., Greenberg, J., Mlddleton, P., Wang, T. (1992). Ozone precursor relationships in the ambient atmosphere. J. Geophys. Res. 97, 60376055. https://doi.org/10.1029/91JD03014

Cheng, K., Hao, W., Yi, P., Zhang, Y., Zhang, J. (2018). Volatile organic compounds emission from Chinese wood furniture coating industry: Activity-based emission factor, speciation profiles, and provincial emission inventory. Aerosol Air Qual. Res. 18, 2813-2825. https://doi.org/10.42 09/aaqr.2018.02.0044

Cheng, N., Jing, D., Zhang, C., Chen, Z., Li, W., Li, S., Wang, Q. (2021). Process-based VOCs source profiles and contributions to ozone formation and carcinogenic risk in a typical chemical synthesis pharmaceutical industry in China. Sci. Total Environ. 752, 141899. https://doi.org/10. 1016/j.scitotenv.2020.141899

Derwent, R.G., Jenkin, M.E., Saunders, S.M. (1996). Photochemical ozone creation potentials for a large number of reactive hydrocarbons under European conditions. Atmos. Environ. 30, 181199. https://doi.org/10.1016/1352-2310(95)00303-G

Fu, S., Guo, M., Luo, J., Han, D., Chen, X., Jia, H., Jin, X., Liao, H., Wang, X., Fan, L., Cheng, J. (2020). Improving VOCs control strategies based on source characteristics and chemical reactivity in a typical coastal city of South China through measurement and emission inventory. Sci. Total Environ. 744, 140825. https://doi.org/10.1016/j.scitotenv.2020.140825

Fu, X., Wang, S., Zhao, B., Xing, J., Cheng, Z., Liu, H., Hao, J. (2013). Emission inventory of primary pollutants and chemical speciation in $\mathbf{2 0 1 0}$ for the Yangtze River Delta region, China. Atmos. Environ. 70, 39-50. https://doi.org/10.1016/j.atmosenv.2012.12.034

Han, X. (2017). Analysis and research on the lampblack and waste gas of dyeing and finishing of textile industry. Beijing Institute of Fashion Technology (in Chinese).

Huang, B., Lei, C., Wei, C., Zeng, G. (2014). Chlorinated volatile organic compounds (Cl-VOCs) in environment - Sources, potential human health impacts, and current remediation technologies. Environ. Int. 71, 118-138. https://doi.org/10.1016/j.envint.2014.06.013

Huang, W., Zhao, Q., Liu, Q., Chen, F., He, Z., Guo, H., Ling, Z. (2020). Assessment of atmospheric photochemical reactivity in the Yangtze River Delta using a photochemical box model. Atmos. Res. 245, 105088. https://doi.org/10.1016/j.atmosres.2020.105088

Khan, F.I., Kr. Ghoshal, A. (2000). Removal of volatile organic compounds from polluted air. J. Loss Prev. Process Ind. 13, 527-545. https://doi.org/10.1016/S0950-4230(00)00007-3

Li, Q., Su, G., Li, C., Liu, P., Zhao, X., Zhang, C., Sun, X., Mu, Y., Wu, M., Wang, Q., Sun, B. (2020). An investigation into the role of VOCs in SOA and ozone production in Beijing, China. Sci. Total Environ. 720, 137536. https://doi.org/10.1016/j.scitotenv.2020.137536

Li, X., Su, W., Li, B., Long, M., Li, L., Zhang, Z., Yu, Y., Wang, Y., Wang, X. (2018). Source profiles and chemical reactivity of volatile organic compounds from surface coating of aluminum products in Foshan, China. Environ. Sci. Technol. 39, 5334-5343. (in Chinese)

Liu, B., Liang, D., Yang, J., Dai, Q., Bi, X., Feng, Y., Yuan, J., Xiao, Z., Zhang, Y., Xu, H. (2016). Characterization and source apportionment of volatile organic compounds based on 1-year of observational data in Tianjin, China. Environ. Pollut. 218, 757-769. https://doi.org/10.1016/j.e nvpol.2016.07.072

Lu, B., Huang, C., Lu, Q., Yang, Q., Jing, B., Xia, Y., Tang, W., Gu, Z. (2018). Emission inventory and pollution characteristics of industrial VOCs in Hangzhou, China. Environ. Sci. 39, 533-542. (in Chinese)

Maji, K.J., Ye, W.F., Arora, M., Nagendra, S.M.S. (2019). Ozone pollution in Chinese cities: 
Assessment of seasonal variation, health effects and economic burden. Environ. Pollut. 247, 792-801. https://doi.org/10.1016/j.envpol.2019.01.049

Martien, P.T., Harley, R.A., Milford, J.B., Russell, A.G. (2003). Evaluation of Incremental Reactivity and Its Uncertainty in Southern California. Environ. Sci. Technol. 37, 1598-1608. https://doi.org/10.1021/es026174t

Mo, Z., Shao, M., Lu, S., Qu, H., Zhou, M., Sun, J., Gou, B. (2015). Process-specific emission characteristics of volatile organic compounds (VOCs) from petrochemical facilities in the Yangtze River Delta, China. Sci. Total Environ. 533, 422-431. https://doi.org/10.1016/j.scitoten v.2015.06.089

Shao, Y. (2019). Study on emission characteristics and emission reduction potential of volatile organic compounds from typical industries. Zhejiang University. (in Chinese)

Song, Y., Dai, W., Shao, M., Liu, Y., Lu, S., Kuster, W., Goldan, P. (2008). Comparison of receptor models for source apportionment of volatile organic compounds in Beijing, China. Environ. Pollut. 156, 174-183. https://doi.org/10.1016/j.envpol.2007.12.014

Thepanondh, S., Varoonphan, J., Sarutichart, P., Makkasap, T. (2011). Airborne volatile organic compounds and their potential health impact on the vicinity of petrochemical industrial complex. Water Air Soil Pollut. 214, 83-92. https://doi.org/10.1007/s11270-010-0406-0

Tian, L., Wei, W., Cheng, S., Li, G., Wang, G. (2017). Source profiles and ozone formation potential of volatile organic compounds from the use of solvent in typical industry. J. Safety Environ. 17, 314-320. (in Chinese)

Wang, H., Zhang, G., Nei, L., Wang, Y., Hao, Z. (2011). Study on control and management for industrial volatile organic compounds (VOCs) in China. Environ. Sci. 32, 3462-3468. (in Chinese)

Wang, J., Iv, J., Li, W., Gu, Z., Miao, X. (2018). Pollution characteristics and emission coefficients of volatile organic compounds from the packaging and printing industry in Zhejiang province. Environ. Sci. 39, 3552-3556. (in Chinese)

Wang, J., Jin, D., Gu, Z., Lu, J., Ye, Z., Dong, S. (2020). The VOCs emission characteristics of metal surface coating industryand its emission factors. China Environ. Sci. 40, 1940-1945. (in Chinese)

Wu, J., Cheng, W., Chao, N. (2015). An inventory for VOCs emissions from anthropogenic sources in Zhejiang province. Shanghai Environ. Sci. 34, 60-66. (in Chinese)

Wu, J., Gao, S., Chen, X., Yang, Y., Fu, Q., Che, X., Jiao, Z. (2020). Source profiles and impact of volatile organic compounds in the coating manufacturing industry. Environ. Sci. Technol. 41, 1582-1588. (in Chinese)

Wu, W., Zhao, B., Wang, S., Hao, J. (2017). Ozone and secondary organic aerosol formation potential from anthropogenic volatile organic compounds emissions in China. J. Environ. Sci. 53, 224-237. https://doi.org/10.1016/j.jes.2016.03.025

Xie, Y., Zheng, X., Liu, C. (2018). Source profiles and ozone formation potental of volatile organic compounds from printing industry in Nanjing. Environ. Sci. Technol. 31, 64-67 (in Chinese).

Xiong, Y., Zhou, J., Xing, Z., Du, K. (2020). Optimization of a volatile organic compound control strategy in an oil industry center in Canada by evaluating ozone and secondary organic aerosol formation potential. Environ. Res. 191, 110217. https://doi.org/10.1016/j.envres.2020.110217

Yang, Y., Yang, J., Yin, S., Yu, Y., Zheng, J., Mo, Z. (2013). Speciated VOCs emission inventory and key species from printing industry in the Pearl River Delta region. Res. Environ. Sci. 26, 326333. (in Chinese)

Yuan, B., Shao, M., Lu, S., Wang, B. (2010). Source profiles of volatile organic compounds associated with solvent use in Beijing, China. Atmos. Environ. 44, 1919-1926. https://doi.org/ 10.1016/j.atmosenv.2010.02.014

Zhang, Y., Li, C., Yan, Q., Han, S., Zhao, Q., Yang, L., Liu, Y., Zhang, R. (2020). Typical industrial sector-based volatile organic compounds source profiles and ozone formation potentials in Zhengzhou, China. Atmos. Pollut. Res. 11, 841-850. https://doi.org/10.1016/j.apr.2020.01.012

Zheng, J., Yu, Y., Mo, Z., Zhang, Z., Wang, X., Yin, S., Peng, K., Yang, Y., Feng, X., Cai, H. (2013). Industrial sector-based volatile organic compound (VOC) source profiles measured in manufacturing facilities in the Pearl River Delta, China. Sci. Total Environ. 456-457, 127-136. https://doi.org/10.1016/j.scitotenv.2013.03.055

Zhong, Z., Sha, Q.E., Zheng, J., Yuan, Z., Gao, Z., Ou, J., Zheng, Z., Li, C., Huang, Z. (2017). Sectorbased VOCs emission factors and source profiles for the surface coating industry in the Pearl 
River Delta region of China. Sci. Total Environ. 583, 19-28. https://doi.org/10.1016/j.scitotenv. 2016.12.172

Ziemann, P.J., Atkinson, R. (2012). Kinetics, products, and mechanisms of secondary organic aerosol formation. Chem. Soc. Rev. 41, 6582-6605. https://doi.org/10.1039/C2CS35122F 